\title{
A technical note on low cost rat laparoscopy an initial experience $^{1}$
}

José Marcus Raso Eulálio', Manoel Luiz Ferreira', Paulo César Silva', José Eduardo Ferreira Manso", Andrei Ferreira Costa Nicolau"', Thales Penna de Carvalho'"', Julia Radicetti de Siqueira Paiva e Silva'v, Adrielle Rodas Fernandes ${ }^{\mathrm{IV}}$, Alberto Schanaider ${ }^{\mathrm{V}}$

'PhD, Associate Professor, Postgraduate Program in Surgical Sciences, Department of Surgery, School of Medicine, Universidade Federal do Rio de Janeiro (UFRJ), Brazil. Technical procedures; acquisition, analysis and interpretation of data, manuscript preparation.

"PhD, Associate Professor, Postgraduate Program in Surgical Sciences, Department of Surgery, School of Medicine, UFRJ, Rio de Janeiro-RJ, Brazil. Acquisition, analysis and interpretation of data.

I'IFellow Master degree, Postgraduate Program, Department of Surgery, School of Medicine, UFRJ, Rio de Janeiro-RJ, Brazil. Technical procedures; acquisition, analysis and interpretation of data.

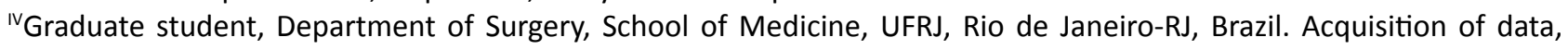
technical procedures.

${ }^{\vee}$ PhD, Full Professor, Head, Centre of Experimental Surgical, Coordinator of Postgraduate Program in Surgical Science, Department of Surgery, School of Medicine, UFRJ, Rio de Janeiro-RJ, Brazil. Intellectual, conception and design of the study, manuscript preparation, critical revision, final approval.

\section{Abstract}

Purpose: To evaluate a novel and adapted low-cost set model for laparoscopic surgery in rats.

Methods: Nine Wistar rats underwent two different laparoscopic procedures, splenectomy $(n=3)$ and distal pancreatectomy with splenectomy $(n=6)$, after assembling a low-cost set replacing the conventional one (monitor, micro camera, image processor, light source, laparoscope and insufflator). The new set included an Android Tablet 10.5 ", a $5 \mathrm{~mm}$ USB Endoscope and semiautomatic sphygmomanometer monitor.

Results: The same surgeon performed the laparoscopic procedures. Total surgical time ranged from 36 to 60 minutes with a mean of 45.8 minutes. Three rats died during the distal pancreatic and splenectomy procedure $(33.3 \%)$, due to respiratory failure $(n=1)$, uncontrolled abdominal hemorrhage $(n=1)$ and iatrogenic gastric perforation $(n=1)$. We followed the other six rats $(66.6 \%)$ for seven days with no further evidence of complications. Conclusions: The laparoscopic partial pancreatectomy and splenectomy can be performed with the novel low-cost set assembled in the present experimental study. Both specific training and skills development are required to validate more advanced laparoscopic procedures and achieve a desirable outcome.

Key words: Laparoscopy. Pancreatectomy. Splenectomy. Models, Animal. Rats. 


\section{Introduction}

During the past 20 years, the development of new surgical techniques such as laparoscopy has improved the treatment of surgical patients by minimizing surgical trauma, accelerating postoperative recovery, and reducing the length of hospital stay ${ }^{1}$. Several complex open surgical techniques can now be performed by minimally invasive surgery. In most clinical trials, higher operating theatre cost is offset by shorter hospital stays, less medication requirements, shorter periods of convalescence, and faster return to work and to normal activity ${ }^{2,3}$.

One of the most commonly used animals in the experimental surgical research is the Wistar rat. This specie is easy to handle and has a low maintenance cost. However, the high-cost of laparoscopic sets and the need for specific techniques for this specimen size are the main limiting points for the development of laparoscopic experimental procedures in rats $^{4,5}$.

Several articles have shown the feasibility of laparoscopic surgery techniques in rats in the last 25 years $^{6-8}$. As a rule, the surgical manipulations and tissue resections are performed using conventional material for human patients adapted to the rat size.

A novel low-cost set adapted for laparoscopic surgery in rats may be useful not only for training this technique, particularly in counties with few financial resources, but also to allow surgical researches that mimic the operative field in humans beings.

\section{Methods}

The study was in conformity to Brazilian law for scientific use of animals and international guiding principles for animal care and was approved by the Ethics Committee for Animal Research of UFRJ.
Nine adult isogenic Wistar rats (Rattus norvegicus albinus), weighing from 250 to $412 \mathrm{~g}$, were obtained from the Centre of Experimental Surgery, School of Medicine of UFRJ. They were housed in appropriate environmental conditions, on a circadian cycle in a temperature-controlled room $\left(24^{\circ} \mathrm{C}\right)$, fed with standard industrial rat chow and water ad libitum.

The study developed a complete laparoscopy set, using low cost surgical instruments, adapted for surgery in rats. The usual set to perform the method presume the availability of (01) monitor, (2) micro camera, (3) image processor, (4) light source, (5) laparoscope and (6) insufflator. The set of instruments proposed in the present study replaced all six items aforementioned and was composed by (1) Android 10.5" Tablet, (2) $5 \mathrm{~mm}$ USB Endoscope and (3) semiautomatic sphygmomanometer monitor (Figure 1).

\section{Tablet android 10.5}

For the surgical procedures, the authors used an Android 10.5" Samsung SMT800 tablet with a 6.0.1 software version. This replaces the monitor and the image processor of the micro camera. The USB Camera program, available free in the Android platform, allows the capture and recording of images (Figure 1).

\section{USB $5 \mathrm{~mm}$ endoscope}

The experimental model used a Digital Supereyes Y003 $5.4 \mathrm{~mm}$ Endoscopy and the Lensoul $5.5 \mathrm{~mm}$ OTG Endoscope. These two models are composed by rigid (Y003) or semirigid (Lensoul) rods, up to $5.5 \mathrm{~mm}$ in diameter, with an USB proximal connection that links to the tablet and another distal end with six led spotlights, and a 2.0 megapixel micro camera. This setting replaces the micro camera, the light source and the laparoscope. These accessories were connected to the $10.5^{\prime \prime}$ tablet 
and displayed appropriate images for the procedures (Figure 1).

\section{Semi-automatic sphygmomanometer monitor}

We used a G-Tech BP3ABOH upper arm semi-automatic pressure device with a battery powered monitor and an insufflation system (Figure 1). It was connected in a Y-shaped rubber tube with one extremity coupled to a $5 \mathrm{~mm}$ trocar and the other to the pressure cuff. At the distal end of the insufflation bulb a $\mathrm{CO}_{2}$ source was connected (Figure 1 - item 3 ).
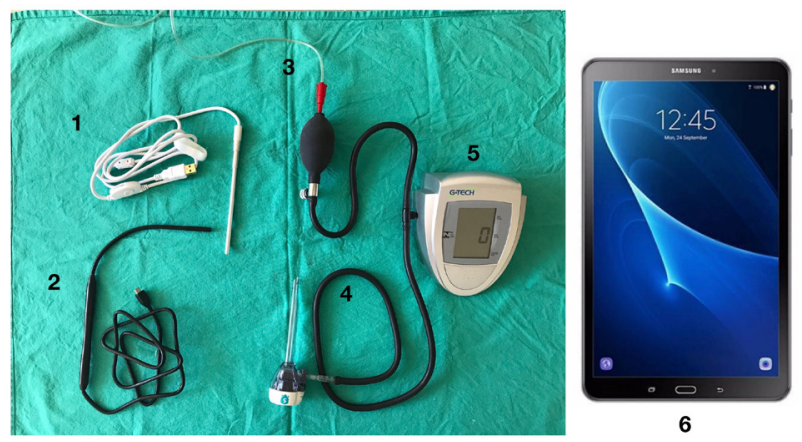

Figure 1 - Set of instruments adapted for laparoscopic surgery in rats. 1. Micro camera with rigid rod $5 \mathrm{~mm}$. 2. Micro camera with flexible rod $5.5 \mathrm{~mm}$. 3. Adaptation of $\mathrm{CO}_{2}$ conductive tube. 4. Detail of the $\mathrm{CO}_{2}$ tube connected to the $5 \mathrm{~mm}$ trocar. 5. Semi-automatic manometer gauged. 6 . Tablet Android 10.5".

A pressure validation test was made to evaluate the G-Tech BP3ABOH manometer with this device. This test consisted of the simultaneous adaptation of a latex glove, which has a quite similar volume to the rat's abdomen, with a Storz insufflator used in medical laparoscopy and the sphygmomanometer monitor. The carbon dioxide insufflation generated equivalent measurements in both insufflator and sphygmomanometer monitors (Figure 2).

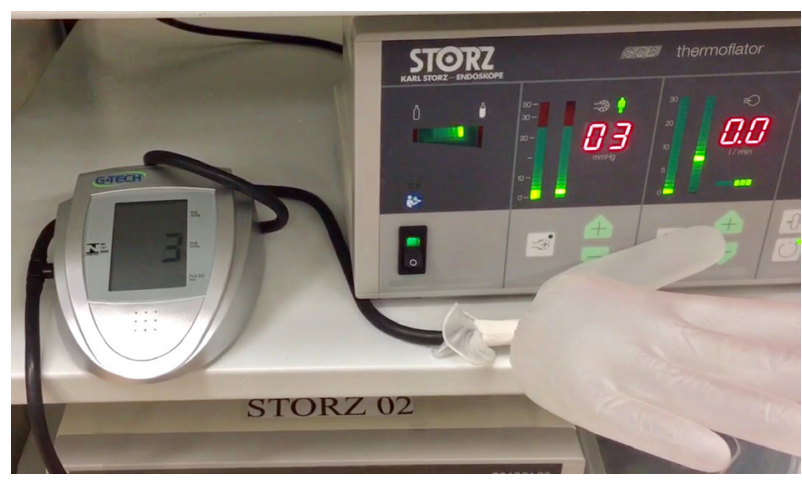

Figure $\mathbf{2}$ - Validation of semi-automatic manometer monitor for experimental use in rats. Latex glove insufflation after simultaneous adaptation to professional insufflator, that brought forth equivalent markings in pressure variations between 1 and $10 \mathrm{mmHg}$. Equivalent measurements can be seen in both insufflator and sphygmomanometer monitors.

\section{Anesthetic and surgical technique}

After $24 \mathrm{~h}$ preoperative fasting, rats underwent general anesthesia by intraperitoneal injection of ketamine hydrochloride solution $(25 \mathrm{mg} / \mathrm{kg})$ and xylazine hydrochloride $(3 \mathrm{mg} / \mathrm{kg})^{9}$. Hydration, when necessary, was given by instillation of $0.9 \%$ sodium chloride solution in the peritoneal cavity under laparoscopic vision. Immediately after anaesthetic administration, animals were immobilized in the dorsal decubitus and the skin over the surgical site was shaved with $10 \%$ polyvinylpyrrolidone-iodine. Upper legs were fixed in minimal extension.

The procedure started with three 1.5 $\mathrm{cm}$ incisions in both left and right iliac fossae and in the middle line over the suprapubic site. Dissection was continued with muscle exposure followed by a single purse-string suture with polyglactin $910\left(\mathrm{Vicryl}^{\circ}\right)$ 4-0, around each incision. Then, the anterior wall of the abdominal cavity was rised by the purse-string sutures in order to allow insertion of the three trocars of $5 \mathrm{~mm}$. The first trocar inserted in the suprapubic site under direct vision was used as 
the USB micro camera port and to insufflate the abdominal cavity. The two remaining trocars were placed under direct vision by the micro camera, previously adapted to the tablet. A careful manual inflation was done until the pressure reached $4.0 \mathrm{mmHg}^{10,11}$ (Figure 3).

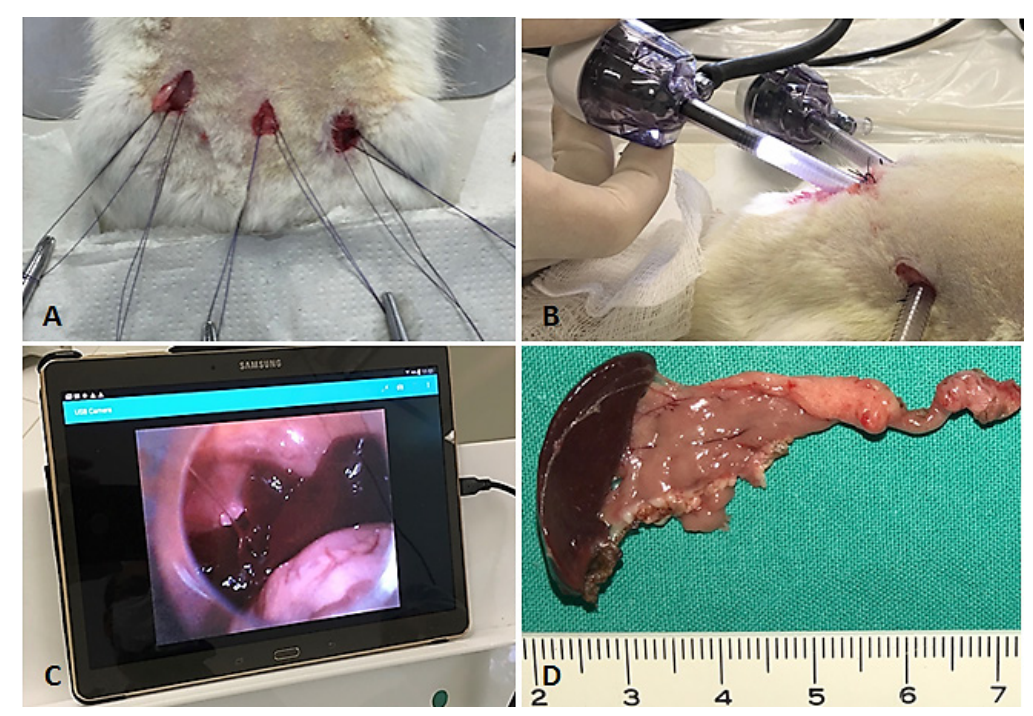

Figure 3 - General aspects of laparoscopic technique. A. The three purse-string suture done. B. Placement of trocars and the micro camera. C. Intra-abdominal image on the tablet screen. D. Resected spleen and distal pancreas.

In addition to the three trocars, the surgical procedures also demanded the following tools: tweezers, $5 \mathrm{~mm}$ scissors and a $5 \mathrm{~mm}$ bipolar forceps. Two surgeons and one anesthesiologist assistant attended all procedures.

The pneumoperitoneum was relieved whenever there was no manipulation to preserve the ventilatory capacity of the specimens. The rats were monitored with oximetry and heart rate monitors.

Postoperative analgesia was provided with dypirone diluted in water at a dose of $30 \mathrm{mg} / \mathrm{kg} /$ day. Behavior, feeding and surgical wounds were evaluated daily. After seven days of follow-up, the animals were killed without pain by isoflurane saturation in a closed camera and laparotomized with evaluation of the cavity, regarding the presence or absence of surgical complications (bruise, fistula, ascites, abscess, hematoma, peritonitis).

\section{- Results}

Total surgical time necessary to complete the organ resections ranged from 36 to 60 minutes with a mean of 45.8 minutes. The pneumoperitoneum time ranged from 23 to 44 minutes with a mean of 30.1 minutes. There were no accidents in the placement of the trocars. No wound infection was found.

Three animals died. The first one due to uncontrolled abdominal hemorrhage immediately after the section of the vascular pedicle of the splenic lobule of the pancreas. The second animal died in the first 24 hours postoperatively and necropsy displayed a gastric perforation at the esophagogastric junction. The third one, died at the end of operation, when abdominal wall was already closed, in consequence of a respiratory failure. The other rats were monitored for seven days and showed no surgical or clinical complications (Table 1). 
Table 1 - Results of 9 laparoscopic procedures in rats.

\begin{tabular}{|c|c|c|c|c|c|c|c|}
\hline Rat & $\begin{array}{l}\text { Weight } \\
\text { (g) }\end{array}$ & $\begin{array}{c}\text { Duration of } \\
\text { the surgery } \\
\text { (min) }\end{array}$ & $\begin{array}{l}\text { Time of pneumo } \\
\text { peritoneum } \\
\text { (min) }\end{array}$ & $\begin{array}{c}\text { Surgical } \\
\text { complications }\end{array}$ & $\begin{array}{c}\text { Outcome } \\
7 \text { days } \\
\text { after }\end{array}$ & $\begin{array}{c}\text { Surgery } \\
\text { Performed }\end{array}$ & $\begin{array}{c}\text { Endoscope } \\
\text { diameter } \\
(\mathrm{mm})\end{array}$ \\
\hline $1^{*}$ & 340 & 60 & 44 & $\begin{array}{l}\text { Death after } \\
\text { bleeding during } \\
\text { the surgery }\end{array}$ & & Splenectomy & 5.5 \\
\hline 2 & 420 & 46 & 40 & & Alive & Splenectomy & 5.5 \\
\hline 3 & 320 & 50 & 30 & $\begin{array}{c}\text { Death in the first } \\
24 \text { hours post- } \\
\text { operative due to } \\
\text { esophagogastric } \\
\text { junction } \\
\text { perforation }\end{array}$ & & $\begin{array}{c}\text { Distal } \\
\text { pancreatectomy } \\
\text { + Splenectomy }\end{array}$ & 5.5 e 5.4 \\
\hline 4 & 380 & 54 & 34 & & Alive & $\begin{array}{c}\text { Distal } \\
\text { pancreatectomy } \\
\text { + Splenectomy }\end{array}$ & 5.5 \\
\hline 5 & 250 & 45 & 25 & $\begin{array}{l}\text { Death due to } \\
\text { hypoxia after } \\
\text { the end of } \\
\text { surgery }\end{array}$ & & $\begin{array}{c}\text { Distal } \\
\text { pancreatectomy } \\
\text { + Splenectomy }\end{array}$ & 5.5 e 5.4 \\
\hline 6 & 460 & 41 & 28 & & Alive & Splenectomy & 5.4 \\
\hline 7 & 380 & 36 & 21 & & Alive & $\begin{array}{c}\text { Distal } \\
\text { pancreatectomy } \\
\text { + Splenectomy }\end{array}$ & 5.5 e 5.4 \\
\hline 8 & 345 & 42 & 23 & & Alive & $\begin{array}{c}\text { Distal } \\
\text { pancreatectomy } \\
\text { + Splenectomy }\end{array}$ & 5.5 \\
\hline 9 & 412 & 38 & 26 & & Alive & $\begin{array}{c}\text { Distal } \\
\text { pancreatectomy } \\
\text { + Splenectomy }\end{array}$ & 5.5 e 5.4 \\
\hline
\end{tabular}

*Female rat.

\section{- Discussion}

Laparoscopy is now the gold standard method for various operations of the digestive, urinary, endocrine and reproductive tract. Their acceptance and consistency of results are accompanied by the development of instruments that enable and facilitate an increasing number of procedures ${ }^{1-3}$. However, the cost of this technology ${ }^{12}$ creates several limitations that hamper the development of experimental models, especially in small animals.

Experimental laparoscopy is a fundamental modality for both training ${ }^{4,5}$ and development of surgical techniques. It is also useful for scientific researches when a minimal invasive surgical procedure is required ${ }^{7,8}$. The laparoscopy causes less trauma ${ }^{13}$, postoperative pain $^{14}$, dehydration due to exposure of loops ${ }^{15}$, and often with fewer postoperative complications. The distal pancreatectomy with splenectomy technique in rats was not found in the literature ${ }^{16}$. 
The cost of acquiring the basic set of devices to perform a laparoscopy varies widely according to the country, manufacturer and model. We found offerings from a semisystem on sale sites (Amazon, EBay) composed by (01) monitor, (2) micro camera, (3) image processor, (4) light source, (5) laparoscope and (6) insufflator, ranging from US\$ 7500 to US\$25000. In Brazil, a new laparoscopic system, with a good quality camera, can easily exceeds US\$ 50000. It becomes even greater in the case of small animals applications that require adaptations and more maintenance expenses. It is almost impossible to cover these high costs if there are no consistent grants for researchers. Moreover, most of the third word and even some developing countries like Brazil cannot afford such expenses in an experimental scenario.

Indeed, the instruments used in this study have very low cost and total sum is up to US\$ 300. A Tablet 10 " costs on average US\$200 (ranging from US\$90 to US\$700). The semiautomatic sphygmomanometer costs from US\$40 to US\$60 and the micro camera from US\$20 to US\$40. Lower accessible prices make it easier to replace any malfunctioning item.

In the present study, these devices were reused without any failure or defect reported. Cleaning for reuse should be immediate and antisepsis with alcoholic chlorhexidine solution did not impair the function of the appliances.

Peritoneal anesthesia with ketamine and xylazine has the advantage of being simple, effective and easily replicable if the animal begins to react ${ }^{9}$. The anesthesiologist assistant had an essential role in the low-cost technique, monitoring the vital parameters and the intraabdominal pressure of the rats and making delicate insufflation when necessary.

It was observed that the fixation of the upper legs in partial extension helps the spontaneous ventilation. Nevertheless, one animal died during the procedure due to the probable effect of the sum of the anesthesia with the pneumoperitoneum. This specimen had the lowest weight (250g) and the smallest dimensions. Anesthesia with intubation and mechanical ventilation was not used, but it surely can be performed to favor the implementation of more complex and timeconsuming procedures with the low-cost instruments.

The Veress needle was tested previously and in such circumstances after making a pursestring suture. The pressure cuff was removed in order to adapt this needle and connect it to the $\mathrm{CO}_{2}$ conducting tube. A Y-shaped system allowed the sphygmomanometer monitorization. In the Veress needle closed method of entry, the abdominal pressure may be increased immediately prior to insertion of the first trocar. We verified that pneumoperitoneum has to be installed only after placement of the three trocars, aiming to decrease the time of overload to the ventilatory function of the animals. Furthermore, the open entry technique with direct insertion without prior pneumoperitoneum was utilized by the authors because it is a safe alternative, faster than the Veress needle technique and probably associated with less insufflationrelated complications such as hypotension and hypoxia. Rising the purse-string sutures, the trocars insertion is facilitated. It is necessary to place the trocars adequately to guarantee the fixation and absence of gas leakage. The escape of gas through the trocars holes makes not only the pneumoperitoneum ineffective but also the procedure unfeasible. The pneumoperitoneum often decreases with manipulation of the tweezers and needs to be gently corrected by the assistant. Moreover, considering the small holes of the trocars, the instrumental manipulation must be gentle, regarding the tweezers weight and movements and also the instrumental mobility. If this care is not followed, air leakage may occur during 
the surgery. Thus, properly maintenance of the pneumoperitoneum pressure is the cornerstone of a successful procedure. Pressures smaller than $3 \mathrm{mmHg}$ do not provide good operative field and those above $6 \mathrm{mmHg}$ generate respiratory failure. Thus it is fundamental to maintain the abdominal pressure between 4 and $6 \mathrm{mmHg}^{4,5,10,11}$. The relief of the pneumoperitoneum in the presence of hypoxia may improve the animal recover, decreasing the mortality rate. It was demonstrated the accuracy of the sphygmomanometer monitor in measuring pressures similarly to the traditional insufflator (pressure variations between 1 and $10 \mathrm{mmHg}$ ) validating the use of such adapted device and the pressure controlled by sphygmomanometer was suitable during all procedures.

The adapted set and the technique used were suitable for viewing and manipulating the intra-abdominal structures by laparoscopy. The left iliac fossa is an adequate site to enable the trocar view for splenectomy and distal pancreatectomy. A common difficulty is the presence of the distended cecum, which must be avoided by the camera movements. The miniaturization and proximity of the instruments used were facilitating factors. Although the definition of 2.0 megapixels is relatively low, visualization of the rat abdominal cavity was possible due to its small dimensions. The quality of the image generated by the camera was sufficient to distinguish dissected structures. Likewise, the illumination generated by the LED spotlights was suitable for the procedure, without any image artifacts. The $5.4 \mathrm{~mm}$ and the $5.5 \mathrm{~mm}$ diameter of the camera allow for reasonable mobility in the cavity and passes through the $5 \mathrm{~mm}$ trocar without damaging the trocar seal mechanism.

The vision of a USB camera processed by a Tablet is inferior to a professional laparoscopic micro camera with 3CCDs. However, the possibility of recognizing the organs, vascular structures and main ducts make this low-cost technology valid. It was used the two cameras. The Supereyes Y003 $(5.4 \mathrm{~mm})$ endoscope, former created for otological evaluation, has the advantage of manually adapting the focus generating very clear images, but in a restricted field. The Lensoul Endoscope $(5.5 \mathrm{~mm})$ is a waterproof (IP67) auto-focus cap that allows better view of larger surgical fields than the other endoscopes. Focus automatism may take longer to compensate the optic movements and generate blurry images soon after moving the optics. Nevertheless, usually this did not disturb any procedure in our study.

Recording is possible but generates a discrete delay in image processing. When phase recording of the procedure was not essential, we preferred to perform it with this function disabled. Tablets with more powerful processors are likely to overcome this limitation.

We have shown that both distal pancreatectomy with splenectomy or splenectomy alone can be safely performed and such resection procedures require the development of surgical skills for dealing with rats $^{17,18}$. The two rat's death because of gastric perforation and intra-abdominal bleeding occurred early, during or on the day after the laparoscopic procedures, but the mortality rate was significantly reduced as soon as the learning curve ended.

Among the limitations of the low-cost set, we highlight the visualization has a small delay regarding to the actual movement, which is almost unnoticeable if there is no simultaneous recording of the video. The screen size is smaller than a regular laparoscopy monitor. Since the insufflator is not automatic, it is necessary that a member of the team exclusively dedicated to handle the insufflation bulb and controlling the intra-abdominal pressure. The 0 o laparoscope is not as capable 
as a 30 o one.

The adaptations of instruments that make up a novel and basic set of laparoscopic surgery in rats were validated in the current study. We believe that within rigid parameters, considering the limitations and potentialities of the equipment, low-cost laparoscopy in rats can improve experimental research and facilitate the development of new experimental models.

\section{Conclusions}

Low-cost laparoscopy in rats is a promising new model of elective laparoscopy. It has a possible translational applicability in complex intra-abdominal operations, mimicking surgical procedures in humans.

\section{References}

1. Sørensen SM, Savran MM, Konge L, Bjerrum F. Three-dimensional versus two-dimensional vision in laparoscopy: a systematic review. Surg Endosc. 2016 Jan;30(1):11-23. doi: 10.1007/s00464-0154189-7. PMID: 25840896.

2. Pang L, Kong J, Wang Y, Zhang Y. Laparoscopic versus open pylorus-preserving pancreatoduodenectomy. The first metaanalyse of retrospective matched cases. Acta Cir Bras. 2018 Jan;33(1):40-48. PMID: 29412232.

3. Kasai M, Cipriani F, Gayet B, Aldrighetti L, Ratti F, Sarmiento JM, Scatton O, Kim KH, Dagher I, Topal B, Primrose J, Nomi T, Fuks D, Abu Hilal M. Laparoscopic versus open major hepatectomy: a systematic review and meta-analysis of individual patient data. Surgery. 2018 May;163(5):985-95. doi:10.1016/j.surg.2018.01.020. PMID: 29555197.

4. van Velthoven RF, Hoffmann P. Methods for laparoscopic training using animal models. Curr Urol Rep. 2006 Mar;7(2):114-9. PMID: 16526995.

5. Martinez AM, Kalach AC, Espinoza DL. Millimetric laparoscopic surgery training on a physical trainer using rats. Surg Endosc. 2008 Jan;22(1):246-9. PMID: 18030523.
6. Ypsilantis P, Simopoulos C. A laparoscopic technique of partial hepatectomy in the rat. J Surg Res. 2016 Oct;205(2):286-91. PMID: 27664874.

7. Meyer F, loshii SO, Chin EW, Esser DM, Marcondes RT, Patriani AH, Pimpão Bde F. Laparoscopic partial nephrectomy in rats. Acta Cir Bras. 2007 Mar-Apr;22(2):152-6. PMID: 17375224.

8. Targarona EM, Espert JJ, Bombuy E, Trias M. Laparoscopic splenectomy in a rat model: developing an easy technique. J Laparoendosc Adv Surg Tech A. 1999 Dec;9(6):503-6. PMID: 10632512.

9. Wellington D, Mikaelian I, Singer L. Comparison of ketamine-xylazine and ketamine-dexmedetomidine anesthesia and intraperitoneal tolerance in rats. J Am Assoc Lab Anim Sci. 2013 Jul;52(4):481-7. PMID: 23849447.

10.Berguer R, Cornelius T, Dalton M. The optimum pneumoperitoneum pressure for laparoscopic surgery in the rat model. A detailed cardiorespiratory study. Surg Endosc. 1997 Sep;11(9):915-8. PMID: 9294272.

11.Gutt CN, Riemer V, Brier C, Berguer R, Paolucci V. Standardized technique of laparoscopic surgery in the rat. Dig Surg. 1998;15(2):135-9. PMID: 9845575.

12.Pędziwiatr $M$, Wierdak $M$, Nowakowski $M$, Pisarska $M$, Stanek $M$, Kisielewski $M$, Matłok M, Major P, Kłęk S, Budzyński A. Cost minimization analysis of laparoscopic surgery for colorectal cancer within the enhanced recovery after surgery (ERAS) protocol: a single-centre, case-matched study. Wideochir Inne Tech Maloinwazyjne. 2016;11(1):14-21. doi: 10.5114/wiitm. 2016.58617. PMID: 28133495.

13.Yiannakopoulou E, Nikiteas N, Perrea D, Tsigris C. Minimally invasive surgery and oxidative stress response: what have we learned from animal studies? Surg Laparosc Endosc Percutan Tech. 2013 Feb;23(1):25-8. PMID: 23386145.

14.Préfontaine $L$, Hélie $P$, Vachon $P$. Postoperative pain in Sprague Dawley rats after liver biopsy by laparotomy versus laparoscopy. Lab Anim (NY). 2015 May;44(5):174-8. doi: 10.1038/laban.731. PMID: 25897938.

15.Takada M, Fukumoto S, Ichihara T, Ku Y, 
Kuroda Y. Comparison of intestinal transit recovery between laparoscopic and open surgery using a rat model. Surg Endosc. 2003 Aug;17(8):1237-40. PMID: 12799882.

16.Eulálio JM, Bon-Habib AC, Soares DO, Corrêa PG, Pineschi GP, Diniz VS, Manso JE, Schanaider A. Critical analysis and systematization of rat pancreatectomy terminology. Acta Cir Bras. 2016 Oct;31(10):698-704. PMID: 27828605.
17.Targarona EM, Espert JJ, Bombuy E, Trias M. Laparoscopic splenectomy in a rat model: developing an easy technique. J Laparoendosc Adv Surg Tech A. 1999 Dec;9(6):503-6. PMID: 10632512.

18.Silva JJ, Silva AL, Paulo DN. Subtotal laparoscopic splenectomy in rats with preservation of the inferior pole. Acta Cir Bras. 2011 Feb;26(1):44-50. PMID: 21271203.

\section{Correspondence:}

José Marcus Raso Eulálio

Centro de Ciências da Saúde, UFRJ

Centro de Cirurgia Experimental

Avenida Carlos Chagas Filho, 373, Bloco J/2응

andar

21941-90 Rio de Janeiro - RJ Brasil

rasoeulalio@globo.com

Received: May 08, 2018

Review: July 10, 2018

Accepted: Aug 07, 2018
Conflict of interest: none

Financial sources: CNPq, FAPERJ
${ }^{1}$ Research performed at Department of Surgery, School of Medicine, Universidade Federal do Rio de Janeiro (UFRJ), Brazil. 